\title{
EL CABILDO DE LA CATEDRAL DE CIUDAD RODRIGO CONTRA RODRIGO ALEMÁN
}

Siempre ha llamado la atención entre los historiadores del arte la existencia de una autorización por parte del cabildo de la catedral de Plasencia permitiendo a Rodrigo Alemán ausentarse para trabajar en la sillería de la catedral de Ciudad Rodrigo. Es ahora, merced a una carta ejecutoria aparecida en el Archivo de la Chancillería vallisoletana fechada el 27 de enero de 1503, cuando podemos dar una explicación de las circunstancias que rodearon ese hecho ${ }^{1}$.

La figura de Rodrigo Alemán es seguramente la mejor conocida de entre todos los escultores europeos que vienen a trabajar a España en torno a 1500. El personaje ha sido objeto de varias publicaciones e incluso de una tesis doctoral, que han servido para acotar su intervención, en lo que respecta a las sillerías de coro, en tres obras seguras: las de Toledo, Plasencia y Ciudad Rodrigo ${ }^{2}$.

El documento encontrado ahora se refiere a esta última y resume un pleito promovido por el Dean y Cabildo de la Catedral de Ciudad Rodrigo contra Rodrigo Alemán, vecino de Toledo y estante en Plasencia, a causa de no dar fianzas ni terminar la sillería de coro de dicha catedral, a lo que se había comprometido años antes en escritura pública. El pleito a que se refiere la carta ejecutoria no ha sido hallado en el archivo de la Chancillería, y eso nos ha privado, seguramente, de encontrar una copia del contrato y algunos otros datos de interés.

La primera noticia sobre la intervención de Rodrigo Alemán en el coro es el asiento que el 10 de julio de 1498 realizó con el deán y cabildo de la catedral de Ciudad Rodrigo, y que se ha conservado en los Libros de Actas Capitulares ${ }^{3}$. En él Rodrigo Alemán se obligaba a realizar dos sillas, una baja y otra alta, cada una valorada en 10.000 maravedíes, con la salvedad de que si valían más nọ le darían las demasías y si valían menos se nombrarían dos peritos, uno por cada parte, que las tasasen. El cabildo se comprometía, si estaba conforme con las muestras, a encargar, a 10.000 maravedíes cada silla o por la cifra menor que dijesen los tasadores, el resto de las sillas del coro a Rodrigo Alemán.

El tiempo transcurrido entre este asiento privado y el contrato público firmado ante notario fue de un año, tiempo necesario para realizar las dos sillas, para que éstas fueran tasadas por dos escultores, y para que el cabildo aceptase la hechura y ambas partes acordasen sellar el acuerdo ante un escribano ${ }^{4}$. Esta escritura fue presentada como prueba por el deán y cabildo de la iglesia mayor mirobrigense ante la justicia, y en la carta ejecutoria se recogen al-

Archivo de la Chancillería de Valladolid, Reales Ejecutorias, Caja 176-47.

2 Arena, Héctor Luis: Die Chorgestiibbe des Meisters Rodrigo Aleman, Buenos Aires, 1995, y «Las sillerías de coro del maestro Rodrigo Alemán», Boletín del Seminario de Estudios de Arte y Arqueología, XXXII, Universidad de Valladolid, 1966, pp. 89-123. Dorothy y Henry Kraus: Las sillerías góticas españolas, Alianza. Forma, Madrid, 1984, sobre todo el capítulo 13. Los temas iconográficos utilizados por Rodrigo Alemán han sido analizados por Isabel Mateo en «Temas iconográficos interpretados por el Maestro Rodrigo Alemán en la sillería de la Catedral de Toledo», Goya, 105, 1971, pp. 158-163; Temas profanos en la escultura gótica española. Las sillerías de Coro, C.S.I.C., Madrid, 1979 y «La batalla de los gigantes de Pollaiuolo en la sillería de coro de la catedral de Ciudad Rodrigo» en Boletín del Seminario de Estudios de Arte y Arqueología, LV, Universidad de Valladolid, 1989, pp. 369-372. Últimamente Dorothee Heim ha realizado un estudio centrado en el origen del maestro y en algunos oficiales de su taller toledano: «El entallador Rodrigo Alemán, su origen y su taller», Archivo Español de Arte, 270, 1995, pp. 131-43.

3 Mateo Hernández Vegas: Ciudad Rodrigo. La catedral y la ciudad, tomo 1, Excelentísimo Cabildo de la Catedral de Ciudad Rodrigo, Salamanca, 1982, pp. 254-5.

4 El transcurso de un año entre el asiento con el cabildo para realizar las muestras y la firma de un contrato firme ante escribano se había repetido poco antes en el caso de la sillería de la catedral de Plasencia, donde Alemán se comprometía a terminar las dos sitiales de los reyes que servirían de muestra para toda la sillería en un año. Mogollón Cano-Cortés, Pilar y Pizarro Gómez, Francisco Javier: La Sillería de Coro de la Catedral de Plasencia, Universidad de Extremadura, Cáceres, 1992, p. 92. 
gunas de sus condiciones. Según el compromiso, fechado en julio de 1499, la obra de la sillería tenía que terminarse en año y medio, es decir por la Navidad de 1500; para ello Rodrigo Alemán se comprometía a contratar a cuatro oficiales para que trabajasen con él en la sillería, y el cabildo se obligaba a pagar 5.000 maravedíes cada mes, que lógicamente habría que descontar del total tasado una vez terminada la obra ${ }^{5}$. En caso de que se paralizasen los trabajos, los canónigos podrían contratar otros oficiales que terminasen los asientos a costa de Rodrigo Alemán. Por último, como garantía, los canónigos exigían al maestro una fianza de 200.000 maravedíes a entregar en un plazo de dos meses.

Una vez firmado el contrato, o incluso antes, como luego veremos, comenzaron los problemas. Rodrigo Alemán se quejó desde un principio del escaso precio de las sillas lo que obligó a los promotores a prometerle 3.000 maravedíes más por silla, hasta alcanzar los 13.000 maravedíes por cada asiento. El escultor comenzó a trabajar en unión de los cuatro oficiales, pero al poco tiempo el maestro abandonó la ciudad dejando solos a sus oficiales, que no tardaron mucho en seguir los pasos del maestro. En este intervalo el cabildo había adelantado unos 300.000 maravedíes poco más o menos ${ }^{6}$, y al ver la obra totalmente paralizada contrataron a dos entalladores ajenos a Alemán, Gille Martín y Alonso de Sevilla, que continuaron las labores durante un tiempo.

Así las cosas, en el verano de 1501 ó 1502 se personó el racionero de la catedral de Ciudad Rodrigo y mayordomo de la obra de la sillería ante el corregidor de la ciudad de Plasencia con una copia de la escritura y un escrito en el que expresaban las obligaciones asumidas por Rodrigo Alemán en dicho contrato, sus incumplimientos en cuanto a ejecución directa de la obra, plazos de terminación, presentación de fianzas, etc. Además señalaba que se le habían adelantado hasta trescientos mil maravedíes sin que éste accediese a finalizar las sillas. Por todo ello exigía — ya que Rodrigo Alemán no hera un hombre «abonado de bienes raíces», es decir propietario de bienes inmuebles que se pudieran embargar, y temiendo que se ausentase sin cumplir el contrato- que el maestro diese fianzas por valor de doscientos mil maravedíes, precio en que se evaluaban las pérdidas de la catedral, o si no que lo «mandase prender e le tuviese bien preso e recabdado, e se lo mandase entregar para que él (el racionero) lo llevase a dicha Cibdad Rodrigo a cabar las dichas syllas».

Rodrigo Alemán respondió presentando diversas alegaciones, algunas tachadas posteriormente por la parte contraria como exclusivamente dilatorias, y con otras que aclaran los motivos que aconsejaron a Rodrigo Alemán a abandonar la obra salmantina. Alega el escultor que se vio obligado a admitir el compromiso de realizar la sillería por la presión que sobre él ejercieron los canónigos: «que la dicha escritura de yguala de que se pretendía ayudar (el racionero), él (Rodrigo Alemán) no la otorgara e syn consentimiento suyo paresçía consentirlo, ya contra su voluntad por la gran potencia de los dichos deán e cabildo, e por estar él preso e en su poder. (...) de manera que sy alguna escritura de yguala aya e paresce ser por él consentida, sea ninguno o a lo menos se devía rescindir». Debido a esa presión el maestro

\footnotetext{
5 Dorotee Heim en la página 141 de su artículo citado examina varios pagos realizados a Rodrigo Alemán en Toledo, y llega a la conclusión de que el maestro cobraba entre 100 y 125 maravedíes diarios como salario y sus oficiales en torno a 55 maravedíes. Si trasladamos estas cifras a Ciudad Rodrigo los jornales del taller de Rodrigo Alemán sumarían más de 8.000 maravedíes mensuales, cifra muy superior a los 5.000 prometidos por el deán y cabildo de la catedral de Ciudad Rodrigo.

6 Tan elevada cantidad tuvo que destinarse al pago de los salarios de Rodrigo Alemán y su taller, y sobre todo a la compra de madera por parte del cabildo. Según el acuerdo privado al que llegaron el cabildo y el maestro en 1498 los materiales corrían por cuenta del maestro, posiblemente y ante las quejas de Maestre Rodrigo, el cabildo acordaría adelantar el dinero destinado a madera y descontárselo al final en el momento de la tasación.
} 
alega que fue capaz de admitir un precio que era mucho menor del debido: «Lo otro por aliende de aquello, en la dicha yguala él fuera en ganando en menos de la mitad del justo presçio, porque cada una de las dichas syllas que el fiziera e tuviera de faser segund la muestra que él diera, valía comunmente diez e syete o diez e ocho mill maravedíes». Además expone que él no se obligó a estar de continuo en la obra «e que bastava questuviesen sus ofiçiales e beedor por sy», y que la obligación de dar fianzas y de la totalidad del compromiso terminó cuando los canónigos llamaron a los dos entalladores ya citados para que terminaran la obra, «los quales (...) entendieron en la obra casy un anno, los quales picaron e dañaron la dicha obra». A cambio de todo lo cual les exigía, como compensación por sus pérdidas, 50.000 maravedíes. Para finalizar alegaba que él no podía residir en Ciudad Rodrigo para encargarse personalmente de la labor de la sillería, ya que tenía contratadas una serie de obras en Plasencia y había prometido con juramento no abandonar dicha ciudad hasta terminarlas.

Según esto, la principal razón esgrimida por el escultor para no cumplir el contrato es que se vio obligado a aceptar la obra, a pesar de estar mal pagada, por la fuerte presión moral que ejerció el cabildo mirobrigense, lo que invalidaba la escritura. Dorothy y Henry Kraus llamaron la atención en su momento sobre lo extraño que resultaba que un artista reconocido como Rodrigo Alemán, que había realizado su primera gran obra, la sillería toledana, por 10.000 maravedíes cada silla baja; y que luego una vez demostrada su valía, había contratado las dos sillas altas de los reyes Católicos de Plasencia por 30.000 maravedíes cada una; pudiera un año más tarde aceptar tallar una sillas valoradas en 10.000 maravedíes o incluso menos ${ }^{7}$. Aunque es entrar en el terreno de la especulación, los hechos pudieron suceder de la siguiente manera. Rodrigo Alemán aceptó tallar las dos sillas placentinas el 7 de junio de 1497 con la esperanza de contratar el resto de la sillería de la nueva catedral, seguramente apoyado por Enrique Egas, maestro a quien se habían encargado planos para realizar el nuevo templo. Sin embargo una vez transcurrido el año estipulado para la terminación de los sitiales de los reyes, el escultor ve cómo el contrato de la sillería placentina se retrasaba. Por ello no es extraño que obligado por la falta de trabajo, el maestro se aviniera a aceptar, un mes después de terminado el contrato con el cabildo de Plasencia, es decir el 10 de julio de 1498, la realización de dos sillas para la catedral de Ciudad Rodrigo por un máximo de 10.000 maravedíes cada una, con unas condiciones claramente peores que las placentinas. Mientras en Plasencia se valoraba cada silla en 30.000 maravedíes y hasta un máximo de 35.000 si así se tasaban, en Ciudad Rodrigo se aclaraba que una vez terminadas las sillas se tasarían y si valieran más de los 10.000 maravedíes presupuestados, esa demasía no se abonaría, mientras que si valieran menos se descontaría lo tasado. En el asiento se especificaba que el cabildo mirobrigense se obligaba, si quedaba contento con las dos sillas de muestra, a dar la totalidad de la obra a Rodrigo Alemán. Seguramente una vez terminadas las dos sillas de Ciudad Rodrigo, la situación de Rodrigo Alemán había cambiado y muy posiblemente te-

7 Dorothy y Henry Kraus: Op. cit., p. 179. Los 10.000 maravedíes en que se tasaron las sillas bajas del coro de la catedral de Toledo, aunque son calaramente menores a los 18.000 maravedíes cobrados por Pyeter Dancart por las sillas bajas del coro de la catedral de Sevilla, no eran una cantidad despreciable. Sobre todo si la comparamos con los 9.000 maravedíes en que Juan de Bruselas contrató en 1503, después de realizar una baja sobre los 10.000 maravedíes iniciales, cada par de sillas altas y bajas del coro de la catedral de Zamora, o los 6.000 maravedíes en que se concertaron las sillas altas del mismo coro que no tuvieran su correspondiente silla baja. Tal diferencia de precio se explica porque en el caso zamorano, tanto la madera y clavazón como el salario de los oficiales y la hechura de las esquinas y escaleras, corrían por cuenta del cabildo zamorano. Guadalupe Ramos de Castro: La catedral de Zamora, Zamora, 1982, pp. 594-600 y María Teresa Teijeira Pablos: Juan de Bruselas y la sillería coral de la Catedral de Zamora, Zamora, 1996, pp. 31-2. 
nía en perspectiva la pronta realización del coro placentino, además de estar encargado de los trabajos en el banco del retablo mayor de la catedral de Toledo ${ }^{8}$. Por todo no es de extranar que se resistiese a firmar el contrato notarial para tallar la sillería de la localidad salmantina. Alemán alegará en el pleito que fue presionado por el deán y cabildo para que se encargase de la obra, no sabemos si eso fue así o bien se trata de una artimaña legal para evitar cumplir un contrato aceptado en condiciones muy poco ventajosas. Lo cierto es que Rodrigo Alemán firma en julio de 1499 un contrato público y comienza una obra que poco después abandona por la mejor remunerada de Plasencia.

Pero volviendo al hilo principal de esta disertación, que no es otro que el del pleito iniciado por el deán y cabildo de Ciudad Rodrigo contra Rodrigo Alemán, se constata la aparición de un gran aliado del escultor que le valdrá para librarse, por lo menos en una primera instancia, de la denuncia. Esta ayuda se la presta el corregidor de Plasencia que, como inmediatamente veremos, era parte interesada.

Vistos por el corregidor placentino los escritos presentados por las partes, respondió al racionero que maestre Rodrigo estaba encargado de reparar el puente de la ciudad, que estaba en gran peligro de hundirse. Por esa causa la ciudad le había mandado que no saliese de Plasencia «so ciertas penas e por juramento» ya que dicha obra sólo se podía hacer en verano cuando bajaban las aguas, y que por lo tanto no era posible dar permiso al escultor para trasladarse a Ciudad Rodrigo hasta que llegase el invierno ${ }^{9}$.

El procurador del deán y cabildo de Ciudad Rodrigo presentó un nuevo alegato rebatiendo el anterior del escultor, que tachaba de dilatorio y no ajustado a derecho, en el que aclaraba que ante las peticiones del maestro sus partes habían admitido subir el precio de cada silla en 3.000 maravedíes ${ }^{10}$, que los contratos se firmaban para cumplirlos y que la posibilidad de contratar otros oficiales que continuasen la obra si el maestro la abandonaba era una pena recogida en la escritura de iguala. Sobre lo alegado por el maestro y el corregidor en relación con las obras contratadas por éste en Plasencia y con el juramento realizado para no salir de la ciudad hasta acabarlas, el procurador del deán y cabildo merovrigenses lo considera nulo ya que existía un contrato anterior con la catedral de Ciudad Rodrigo que lo obligaba en primer lugar. Por todo lo cual volvía a pedir que se conminase al escultor a dar fianzas y a acudir a la ciudad salmantina a terminar la sillería.

Tras este nuevo escrito el corregidor placentino dictó sentencia en la que mandaba suspender el pleito hasta septiembre, ya que si permitía salir de la ciudad de Plasencia a maestre Rodrigo «no podría ser syn mucho dapno e perjuiçio de la dicha çibdad de Plazençia y de la obra de la dicha puente que tenía a cargo, syendo como hera notorio la neçesydad de la dicha obra de la dicha puente, la qual sy çesase sería en gran dapno e perjuizio e mucho peligro de la dicha çibdad, de la dicha obra, de los caminantes e de los que tenían neçesidad e pasavan cada día por el dicho rrío do se fazía la dicha puente».

El deán y cabildo de Ciudad Rodrigo en desacuerdo total con la sentencia apelaron ante la Real Chancillería de Valladolid. Ante el alto tribunal argumentaron que Rodrigo Alemán había abandonado la obra de Ciudad Rodrigo después de haberle pagado muchos maravedíes

8 José Ignacio Hernández Redondo y Manuel Arias Martínez: «La silla de Rodrigo Alemán en el Museo Nacional de Escultura», Estudios de Arte. Homenaje al profesor Martín González, Universidad de Valladolid, 1995, p. 375.

9 La realización del puente de Plasencia es la única intervención documentada de nuestro maestro en una obra arquitectónica. Salvador Andrés Ordax: «Arte y urbanismo de Plasencia en la Edad Media», Norba-Arte, T. 22, 1988, p. 59.

10 Según este nuevo precio las 72 sillas del coro de Ciudad Rodrigo costaron 936.000 maravedíes. 
para irse a «la dicha çibdad de Plazençia donde avía estado e estaba façiendo e labrando otras syllas»; cargaron las tintas contra él acusándole de ser el causante de que la obra «que asy dexara començada» estuviese «toda perdida e destruyda», y le tacharon de «ombre fujetivo e no abonado ${ }^{11}$, e sy se fuese e absentase la dicha obra de los dichos sus partes quedaría del todo destruyda», solicitando que se le condenase a dar las fianzas y a terminar la obra.

El tribunal vallisoletano mandó traslado de la petición al escultor, el cual no contestó por lo que fue declarado en rebeldía. «E en su rrebeldía fue avido el dicho pleito» y dictada sentencia definitiva el 23 de diciembre de 1502, por la que Rodrigo Alemán fue condenado a pagar las fianzas en veinte días y a acabar la obra en los seis meses siguientes, so pena de pagar 100.000 maravedíes al deán y cabildo de multa. Además se mandaba que fuese un alguacil de la Chancillería a prenderlo a Plasencia y llevarlo a Ciudad Rodrigo, y a pagar las costas que se tasaron en 3.410 maravedíes.

La sentencia fue claramente contraria a los intereses de Rodrigo Alemán, y no dejaba mucho margen de maniobra para el escultor y el cabildo de Plasencia que veía cómo el maestro debía abandonar su ciudad para trasladarse hasta Ciudad Rodrigo. Sin embargo los canónigos de Ciudad Rodrigo se vieron obligados a negociar con los de Plasencia, y a cambio de que estos últimos permitieran a Rodrigo Alemán abandonar su ciudad, el racionero de aquélla admitió el 27 de marzo de 1503 que «cada quando ... los señores deán e cabildo de la iglesia de Plasencia le enbíen llamar (a Rodrigo Alemán) que venga a entender en las obras de la iglesia de esta çibdad, le darán licencia dentro de tres días para que venga a esta çibdad de Plasençia». Parece por tanto que aunque Rodrigo Alemán perdió el pleito y fue obligado a realizar una obra de escasos emolumentos como era la sillería de Ciudad Rodrigo, consiguió compatibilizarlas con la mejor remunerada de Plasencia ${ }^{12}$.

LUIS VASALLO TORÁNZO Universidad de Valladolid

11 En esta calificación, por otra parte totalmente falsa, de Rodrigo Alemán como fugitivo y no abonado, es decir como hombre no avencidado en ninguna ciudad (lo estaba en Toledo) y no poseedor de bienes raíces embargables, encontramos la única posible referencia a su situación de extranjero. El origen de Rodrigo Alemán, al que en el documento se cita indistintamente como «maestre Rodrigo» o «maestre Rodrigo Alemán, entallador», es todavía hoy motivo de controversia entre los que le consideran procedente del Bajo Rin y los que lo hacen descender de Flandes. La última aportación realizada por Dorothee Heim (Art. cit., pp. 133-9) que atendiendo a motivos iconográficos y formales lo hace descender de Flandes, enlaza con la declaración del entallador Rodrigo Enrique, que declaraba en 1524 que su padre, el maestro Rodrigo, era «flamenco e hidalgo» (María Luz Rokiski Lázaro: «proceso del Tribunal de la Inquisición de Cuenca contra el entallador Rodrigo Enrique», Archivo Español de Arte, 307, 1979, p. 358).

${ }_{12}$ Mogollón Cano-Cortés, Pilar y Pizarro Gómez, Francisco Javier: Op. cit., p. 93. 